\title{
Minimizing complications after minimally invasive surgery for epiphrenic diverticula of the esophagus: technical tips
}

\author{
Fernando A. M. Herbella', Marco G. Patti ${ }^{2}$ \\ 'Department of Surgery, Escola Paulista de Medicina, Federal University of São Paulo, São Paulo, SP 04037-003, Brazil. \\ 2Department of Surgery, University of North Carolina at Chapel Hill, Chapel Hill, NC 27599, USA.
}

Correspondence to: Dr. Fernando A. M. Herbella, Department of Surgery, Escola Paulista de Medicina, Federal University of São Paulo, Rua Diogo de Faria 1087 cj 301, São Paulo, SP 04037-003, Brazil. E-mail: herbella.dcir@epm.br

How to cite this article: Herbella FAM, Patti MG. Minimizing complications after minimally invasive surgery for epiphrenic diverticula of the esophagus: technical tips. Mini-invasive Surg 2020;4:82. http://dx.doi.org/10.20517/2574-1225.2020.84

Received: 19 Aug 2020 First Decision: 16 Sep 2020 Revised: 16 Sep 2020 Accepted: 19 Oct 2020 Published: 6 Nov 2020

Academic Editor: Uberto Fumagalli Romario Copy Editor: Cai-Hong Wang Production Editor: Jing Yu

\begin{abstract}
Epiphrenic diverticula occur within the distal $10 \mathrm{~cm}$ of the esophagus. Because they are secondary to an underlying esophageal motility disorder, the surgical treatment of these diverticula must include a myotomy in addition to the resection of the diverticulum. In selected cases, the diverticulum can be left in place, performing only the myotomy and the partial fundoplication. Most patients will eventually become asymptomatic and the diverticulum can be left in place. Overall, it is a challenging operation that may be associated to significant morbidity. In this review, we illustrate the key technical elements and how to troubleshoot eventual problems.
\end{abstract}

Keywords: Esophageal epiphrenic diverticulum, high resolution manometry, esophageal motility disorders, achalasia, diverticulectomy, esophageal myotomy

\section{INTRODUCTION}

Esophageal diverticula are an uncommon disorder with an incidence less than $4 \%$ in endoscopic and radiologic series ${ }^{[1]}$. They are located above the sphincters that delimit the esophagus (epiphrenic diverticulum for the lower esophageal sphincter and Zenker's diverticulum for the upper esophageal sphincter) and are secondary to dysfunction of these sphincters. This leads to increased pressure and herniation of the mucosa through gaps in the muscular layer (pulsion pseudodiverticulum) or in the

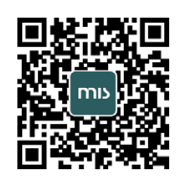




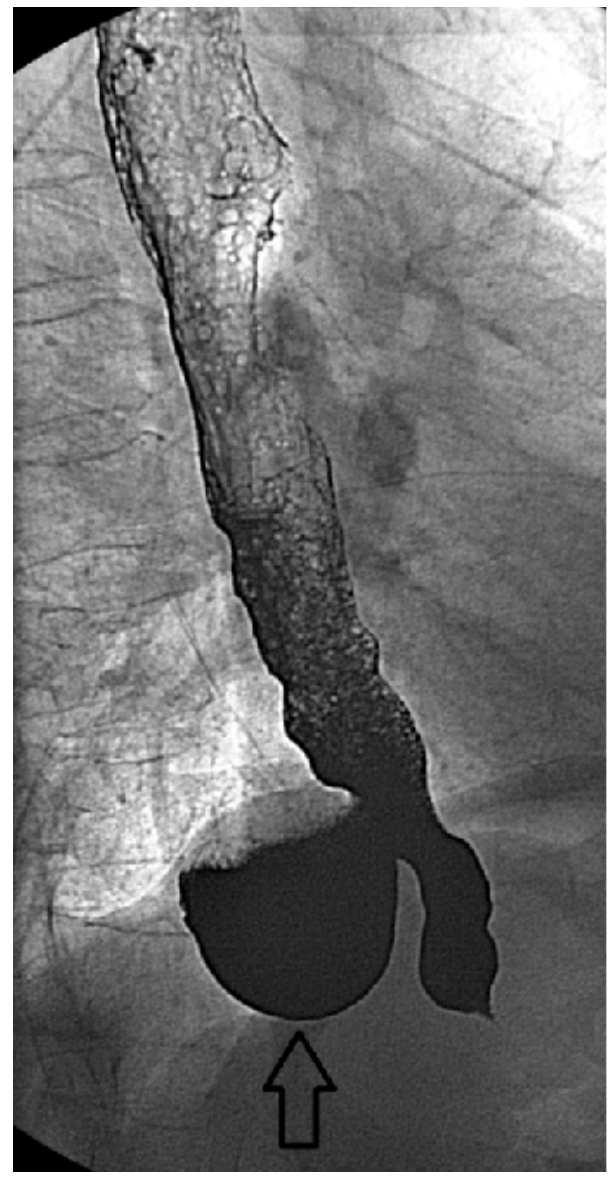

Figure 1. Barium esophagram disclosing an epiphrenic diverticulum (arrow)

esophageal body (Rokitansky diverticulum), classically linked to the tuberculosis era when inflamed mediastinal lymph nodes were believed to create adhesions to the esophageal wall (true traction diverticulum $)^{[2]}$, although recent studies also showed the role of dysmotility in the genesis of these diverticula ${ }^{[3]}$.

Zenker's diverticulum is located in the area of the upper esophageal sphincter and treated by either an open cervical or an endoscopic approach ${ }^{[1]}$. Midthoracic diverticula are usually asymptomatic ${ }^{[3]}$ and represent only $15 \%$ of the esophageal diverticula ${ }^{[4]}$. Intramural pseudodiverticulosis is a rare condition mostly linked to the mucosa ${ }^{[5]}$. These conditions are not treated here.

Epiphrenic diverticulum (ED) [Figure 1] occurs within the distal $10 \mathrm{~cm}$ of the esophagus ${ }^{[2]}$. It is associated to esophageal dysmotility ${ }^{[6]}$. The most common named esophageal motility disorder linked to this disease is achalasia ${ }^{[7]}$. ED is usually treated by a minimally invasive approach, but some series show suboptimal outcomes with up to $23 \%$ leak rate and $20 \%$ need for a reoperation ${ }^{[8]}$. In this series dedicated to Postoperative Complications and Recovery of Minimally Invasive Esophageal Surgery, we may propose three points for discussion as technical tips to improve outcomes and minimize complications in the treatment of ED: conservative approach in selected cases, the abdominal approach when surgical therapy is indicated, and the isolated treatment of the esophageal dysmotility without diverticulectomy.

\section{ABDOMINAL APPROACH}

Most authors advocate the surgical treatment for ED with a cardiomyotomy (Heller's operation) and diverticulectomy ${ }^{[8-10]}$. This form of treatment was historically performed through a thoracotomy. In the 
era of minimally invasive surgery, thoracoscopy replaced thoracotomy as the preferred approach ${ }^{[9]}$. The thoracic approach gained popularity due to easy access to the diverticulum, especially in situations when its ostium is more proximal into the esophagus. The thoracic route has some disadvantages as compared to the abdominal approach that goes farther than the pulmonary morbidity and pain. The myotomy is associated to worse outcomes when performed through the chest as compared to the abdominal route, especially due to a high rate of gastroesophageal reflux ${ }^{[1]]}$. In addition, the development of staplers made easier the resection of the diverticulum via laparoscopy ${ }^{[9]}$. These advantages shifted the preference of modern authors to the laparoscopic route ${ }^{[8]}$. In addition, the laparoscopic approach allowed the performance of a partial fundoplication after the myotomy to prevent pathologic reflux.

When outcomes are compared, disease recurrence is rare for both approaches ${ }^{[8]}$ and the results seem to be similar for thoracoscopy and laparoscopy ${ }^{[8,12-14]}$. If diverticulectomy is considered important (due to symptoms) after a laparoscopic myotomy and partial fundoplication, a thoracoscopic diverticulectomy is safer.

Some technical tips may result in better outcomes ${ }^{[10]}$. First, dissection of the upper border of the diverticulum and of its neck is the most challenging aspect of the laparoscopic route. Even though the diverticulum may appear to be located high in the esophagus, dissection of adhesions to surrounding tissues and sufficient traction of the diverticulum and esophagus with a Penrose drain circling the esophagogastric junction frequently allows dissection of high diverticula from below. It is important to dissect the neck of the diverticulum free of the surrounding tissue and to clearly identify the muscle layers. It must be remembered that ED is pseudodiverticulum, thus muscular fibers cannot be found at the diverticulum itself. Some authors add an extra port for further assistance ${ }^{[15]}$.

If the diverticulum will be resected, it is better performed on the opposite side of the diverticulum to avoid interference with the resection and the muscle closure at that site. If the diverticulum will not be resected, myotomy can be performed at the level of the neck of the diverticulum and extend onto the gastric wall as in a Heller myotomy for achalasia. For the diverticulectomy, a 50-56-F bougie is placed inside the esophagus to avoid narrowing of the lumen when the stapler is applied. Reticulating staplers should be preferentially used to facilitate optimal positioning across the neck of the diverticulum, and the staple height should be appropriate for the thickness of the tissue at the transection site. The muscle layers should be approximated over the staple line with interrupted stitches. A partial fundoplication completes the procedure [Figure 2].

\section{Treatment of the dysmotility without diverticulectomy}

An esophageal motor disorder is present in the majority, if not in all, patients with $\mathrm{ED}^{[6,10]}$. A cardiomyotomy is always necessary when treating a symptomatic diverticulum, even if a dysmotility was not detected by esophageal manometry because: (1) an esophageal dysmotility may not be detected by conventional parameters and be missed by unexperienced physiologists ${ }^{[6]}$; (2) esophageal dysmotility such as achalasia rather than the diverticulum per se may be responsible for most of the symptoms, such as dysphagia and pulmonary symptoms ${ }^{[10,16]}$; and (3) the addition of a myotomy decreases the chance of leak due to a lower intraluminal pressure ${ }^{[17]}$.

A recent systematic review and meta-analysis with 511 patients ${ }^{[14]}$ showed that the diverticulum was left in situ in only $7 \%$ of the cases, mostly due to small size. Castrucci et al ${ }^{[18]}$ also did not perform a diverticulectomy in the presence of wide-necked diverticula without food retention in the pouch, pulmonary aspiration, or mucosal lesions. D'Journo et al. ${ }^{[19]}$ advocated suspension of wide-necked diverticula when there is no dependent portion of the diverticular sac and myotomy alone in the presence of multiple small diverticula. Interestingly, outcomes were similar when the diverticula were resected or left in place. 


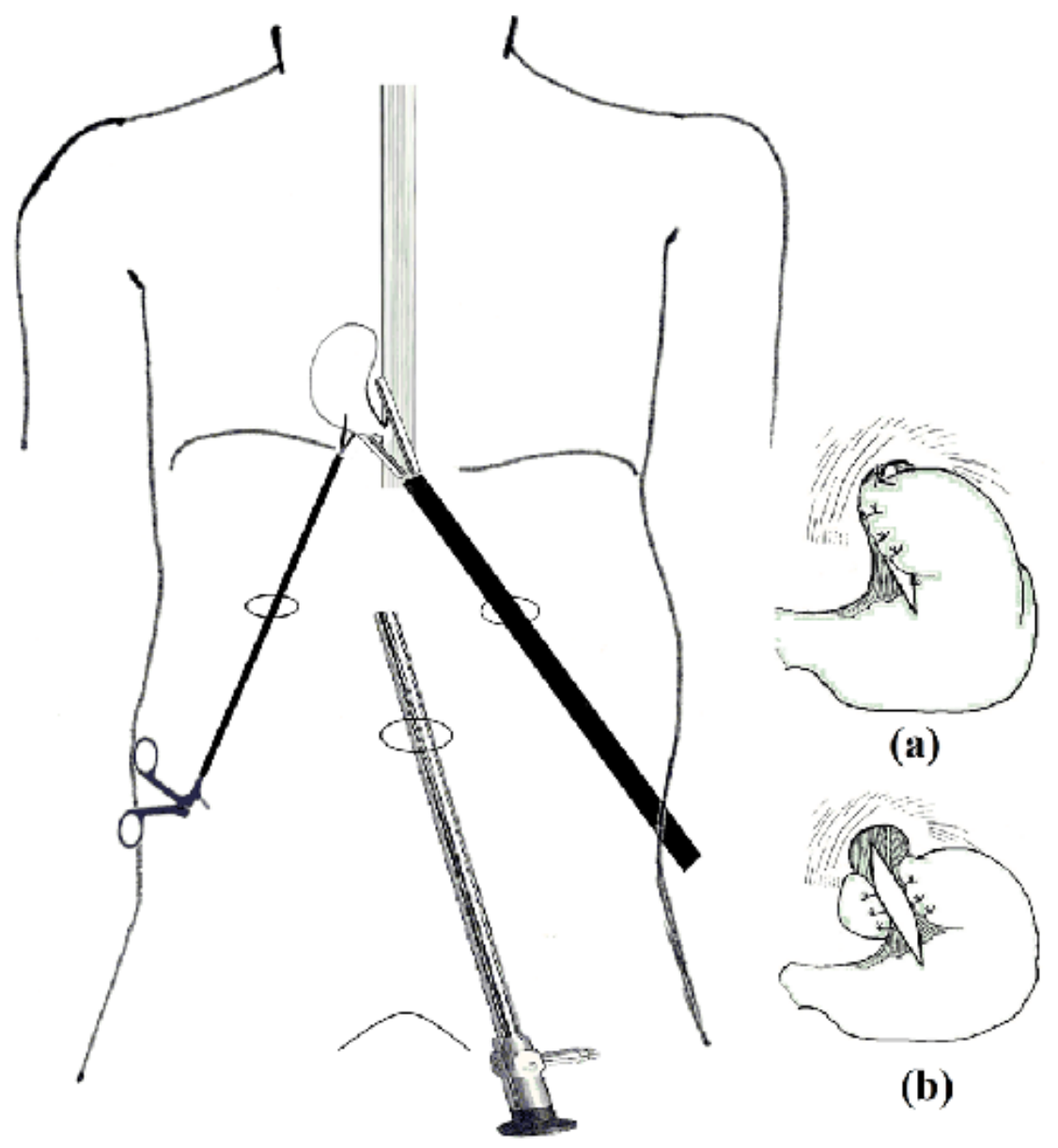

Figure 2. Laparoscopic resection of epiphrenic diverticulum (left). The operation also includes a myotomy and partial fundoplication, either a Dor (a) or Toupet (b). Reproduced from Reference ${ }^{[1]}$ with permission by Springer

Allaix et al. ${ }^{[20]}$ compared the outcomes for resected versus non-resected diverticula in a multicenter study. Among 13 patients, in seven the diverticulum was not excised. The reasons for this approach were small size or technical reasons (the upper pole could not be safely dissected laparoscopically because it was too far from the esophagogastric junction or because of severe adhesions). Similar symptomatic outcomes were documented after 20 months.

If diverticulectomy is not necessary for symptomatic relief, endoscopic treatment for the motor disorder, such as forceful dilatation of the cardia, per oral endoscopic myotomy may be an attractive option. Initial results are promising, albeit mostly based on few case reports ${ }^{[17,21-23]}$.

\section{Conservative treatment}

Some ED are asymptomatic or present with few symptoms ${ }^{[1]}$. This ED may be left untreated.

Some authors investigated the fate of untreated diverticula. Castrucci et al ${ }^{[18]}$ followed up 13 patients for 64 months and showed no complications or worsening of pre-existing symptoms and no change in size (except for one case). Zaninotto et al. ${ }^{[24]}$ followed up 16 patients for 46 months in whom the conservative approach was followed because of the small size of the diverticula or the presence of severe comorbidities. Symptoms were mostly unchanged. The same authors reviewed the literature with similar results reported by five other studies $^{[25]}$. 


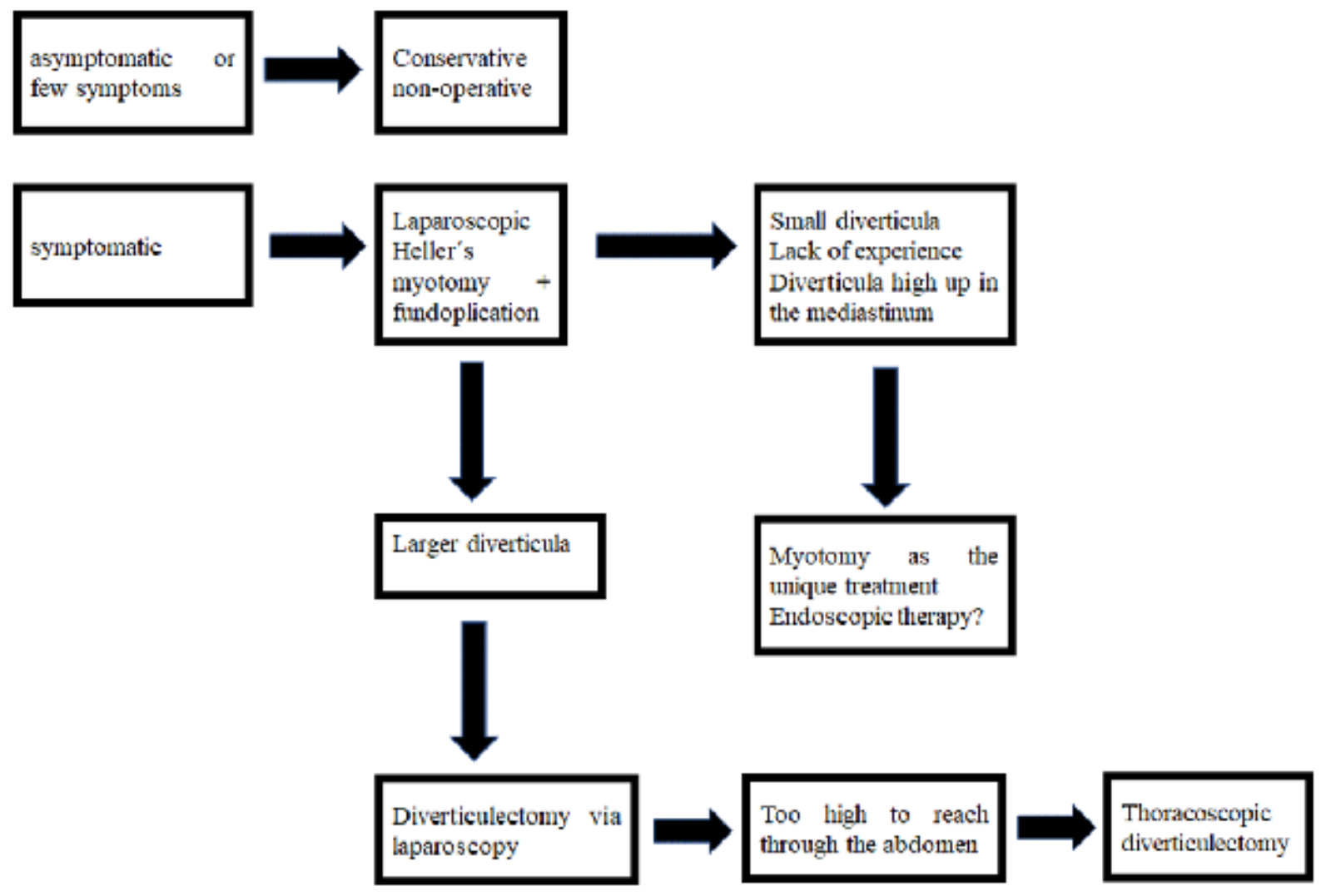

Figure 3. Schematic treatment selection tree diagram for epiphrenic diverticula

Some authors opt for treatment irrespective of symptoms due to the fear of aspiration of the contents of the diverticulum. Symptoms of nocturnal intermittent aspiration are frequent ${ }^{[25]}$; however, cases of pneumonia are $\operatorname{rare}^{[26,27]}$.

The risk of malignant transformation is negligible and does not justify an operation in asymptomatic patients ${ }^{[13]}$.

\section{CONCLUSION}

ED treatment may be associated to high morbidity and mortality in up to $4 \%$ of cases ${ }^{[18]}$. Thus, these patients should be preferably treated in centers with a high volume and expertise in esophageal surgery. A conservative nonoperative approach is acceptable in asymptomatic or oligosymptomatic patients since the risk for severe aspiration and cancer is exceptionally low. When surgery is indicated, the laparoscopic approach should be favored as results are similar to the thoracoscopy approach, but it allows the performance of a partial fundoplication to prevent pathologic reflux. Treatment of the underlying motor disorder is imperative to relieve symptoms and prevent leaks when a diverticulectomy is performed ${ }^{[17]}$, but the resection of the diverticulum may not to be necessary when they are small or very high up in the mediastinum. A treatment selection tree diagram is provided in Figure 3. Endoscopic therapy is waiting a careful evaluation but seems to be a promising alternative.

\section{DECLARATIONS}

\section{Authors' contributions}

Conception and design, acquisition of data, analysis and interpretation of data, drafting the article: Herbella FAM 
Conception and design, review for intellectual content, final approval of the version to be published: Patti MG

\section{Availability of data and materials}

Not applicable.

\section{Financial support and sponsorship}

None.

\section{Conflicts of interest}

All authors declared that there are no conflicts of interest.

\section{Ethical approval and consent to participate}

Not applicable.

\section{Consent for publication}

Not applicable.

\section{Copyright}

(c) The Author(s) 2020.

\section{REFERENCES}

1. Herbella FA, Patti MG. Modern pathophysiology and treatment of esophageal diverticula. Langenbecks Arch Surg 2012;397:29-35.

2. Smith CD. Esophageal strictures and diverticula. Surg Clin North Am 2015;95:669-81.

3. Rice TW, Baker ME. Midthoracic esophageal diverticula. Semin Thorac Cardiovasc Surg 1999;11:352-7.

4. Dado G, Bresadola V, Terrosu G, Bresadola F. Diverticulum of the midthoracic esophagus: pathogenesis and surgical treatment. Surg Endosc 2002;16:871.

5. Herter B, Dittler HJ, Wuttge-Hannig A, Siewert JR. Intramural pseudodiverticulosis of the esophagus: a case series. Endoscopy 1997;29:109-13.

6. Vicentine FP, Herbella FA, Silva LC, Patti MG. High resolution manometry findings in patients with esophageal epiphrenic diverticula. Am Surg 2011;77:1661-4.

7. Herbella FA, Patti MG. Achalasia and epiphrenic diverticulum. World J Surg 2015;39:1620-4.

8. Kilic A, Schuchert MJ, Awais O, Luketich JD, Landreneau RJ. Surgical management of epiphrenic diverticula in the minimally invasive era. JSLS 2009;13:160-4.

9. Andolfi C, Wiesel O, Fisichella PM. Surgical treatment of epiphrenic diverticulum: technique and controversies. $J$ Laparoendosc Adv Surg Tech A 2016;26:905-10.

10. Soares R, Herbella FA, Prachand VN, Ferguson MK, Patti MG. Epiphrenic diverticulum of the esophagus. From pathophysiology to treatment. J Gastrointest Surg 2010;14:2009-15.

11. Allaix ME, Herbella FA, Patti MG. The evolution of the treatment of esophageal achalasia: a look at the last two decades. Updates Surg 2012;64:161-5.

12. Zaninotto G, Portale G, Costantini M, Zanatta L, Salvador R, Ruol A. Therapeutic strategies for epiphrenic diverticula: systematic review. World J Surg 2011;35:1447-53.

13. Herbella FA, Dubecz A, Patti MG. Esophageal diverticula and cancer. Dis Esophagus 2012;25:153-8.

14. Chan DSY, Foliaki A, Lewis WG, Clark GWB, Blackshaw GRJC. Systematic Review and Meta-analysis of SurgicalTreatment of NonZenker's Oesophageal Diverticula. J Gastrointest Surg 2017;21:1067-75.

15. Ueda, Y, Tsunoda S, Hisamori S, et al. Laparoscopic surgery for ventrally located epiphrenic diverticulum with esophageal achalasia. Clin J Gastroenterol 2020;13:491-4.

16. Schlottmann F, Neto RML, Herbella FAM, Patti MG. Esophageal achalasia: pathophysiology, clinical presentation, and diagnostic evaluation. Am Surg 2018;84:467-72.

17. Maydeo A, Patil GK, Dalal A. Operative technical tricks and 12-month outcomes of diverticular peroral endoscopic myotomy (D-POEM) in patients with symptomatic esophageal diverticula. Endoscopy 2019;51:1136-40.

18. Castrucci G, Porziella V, Granone PL, Picciocchi A. Tailored surgery for esophageal body diverticula. Eur J Cardiothorac Surg 1998;14:380-7.

19. D'Journo XB, Ferraro P, Martin J, Chen LQ, Duranceau A. Lower oesophageal sphincter dysfunction is part of the functional abnormality in epiphrenic diverticulum. Br J Surg 2009;96:892-900. 
20. Allaix ME, Borraez Segura BA, Herbella FA, Fisichella PM, Patti MG. Is resection of an esophageal epiphrenic diverticulum always necessary in the setting of achalasia? World J Surg 2015;39:203-7.

21. Yang J, Zeng X, Yuan X, et al. An international study on the use of peroral endoscopic myotomy (POEM) in the management of esophageal diverticula: the first multicenter D-POEM experience. Endoscopy 2019;51:346-9.

22. Demeter M, Ďuriček M, Vorčák M, Hyrdel R, Kunda R, Bánovčin P. S-POEM in treatment of achalasia and esophageal epiphrenic diverticula - single center experience. Scand J Gastroenterol 2020;55:509-14.

23. Kinoshita M, Tanaka S, Kawara F, et al. Peroral endoscopic myotomy alone is effective for esophageal motility disorders and esophageal epiphrenic diverticulum: a retrospective single-center study. Surg Endosc 2020; doi: 10.1007/s00464-019-07340-6.

24. Zaninotto G, Portale G, Costantini M, et al. Long-term outcome of operated and unoperated epiphrenic diverticula. $J$ Gastrointest Surg 2008,12:1485-90

25. Tedesco P, Fisichella PM, Way LW, Patti MG. Cause and treatment of epiphrenic diverticula. Am J Surg 2005;190:891-4.

26. Nehra D, Lord RV, DeMeester TR, et al. Physiologic basis for the treatment of epiphrenic diverticulum. Ann Surg 2002;235:346-54.

27. Altorki NK, Sunagawa M, Skinner DB. Thoracic esophageal diverticula. Why is operation necessary? J Thorac Cardiovasc Surg 1993;105:260-5. 